\title{
Ukleščene dimeljske kile pri otrocih
}

\section{Incarcerated inguinal hernias in children}

Polona Studen Pauletič

\section{Izvleček}

Uvod. Pri otrocih je dimeljska kila najpogostejše stanje, ki zahteva kirurško zdravljenje. Ker ukleščena kila lahko ogroža prekrvitev črevesa, je nujno stanje. Ukleščeno kilo moramo pravočasno prepoznati in ustrezno ukrepati.

Metode. Pregledali smo literaturo in opravili statistični pregled obravnav ukleščenih kil v Univerzitetnem kliničnem centru Ljubljana v petletnem obdobju od januarja 2015 do septembra 2019.

Rezultati. Po navedbah v literaturi delež ukleščenih kil pri otrocih ocenjujejo na 0,9-3\%. V Univerzitetnem kliničnem centru Ljubljana smo v obdobju od januarja 2015 do septembra 2019 obravnavali 32 ukleščenih kil in jih v 12 primerih uspešno reponirali. Sicer smo v tem obdobju pri otrocih elektivno operirali 897 dimeljskih kil. Delež ukleščenih kil je bil 2,1\%.

Zaključek. Delež ukleščenih kil pri nas je primerljiv s podatki v literaturi. Za otroke do 2. leta starosti je smiselna centralizirana obravnava v ustanovah z ustrezno usposobljenim osebjem, ki otrokom nudi optimalno predoperativno oskrbo ter medoperativno in pooperativno podporo. Na vsak način moramo ukleščene kile čim prej prepoznati in jih reponirati.

Ključne besede: dimeljska kila otroci, ukleščena kila.

\begin{abstract}
Introduction. Inguinal hernia is the most common condition requiring surgical treatment in children. Incarceration describes a hernia that cannot be reduced by manipulation. Strangulation refers to vascular compromise of the contents of an incarcerated hernia and is, therefore, a surgical emergency. Strangulation can be avoided when incarceration is promptly recognised and treated.

Methods. We performed a review of the literature on incarcerated inguinal hernia and performed statistical analysis of incarcerated inguinal hernias treated in the University Medical Centre Ljubljana in the last 5 years.

Results. According to the literature, the incidence of incarcerated and irreducible inguinal hernia in children ranges between 0.9-3\%. Between January 2015 and September 2019, in the University Medical Centre Ljubljana, 32 patients were treated for incarcerated hernia, with manual repositioning being successful in 12. In that period, 897 children underwent elective surgery for inguinal hernias. The incidence of incarcerated hernia in children in our centre was $2.1 \%$.

Conclusion. The incidence of incarcerated hernia in our institution is comparable to the published results. Children under the age of two years should be managed in centres with proper equipment and trained staff. It is of utmost importance to promptly recognise and treat a child with an incarcerated hernia by repositioning the hernia.
\end{abstract}

Key words: inguinal hernia children, incarcerated hernia. 


\section{Uvod}

Dimeljska kila je pri otrocih najpogostejše stanje, ki zahteva kirurško zdravljenje (1). Prirojeno dimeljsko kilo ugotavljamo pri 1-5 \% vseh novorojenčkov in pri 9-11\% nedonošenčkov (2). Pri večini otrok $z$ dimeljsko kilo so simptomi blagi, diagnosticiranje enostavno in zdravljenje brez zapletov. Možen zaplet, ki se ga pri dimeljski kil posebej bojimo, je ukleščenje s strangulacijo. Pomembno je, da ukleščeno kilo pravočasno prepoznamo in ustrezno ukrepamo.

Ukleščenje pomeni, da kile ni mogoče reponirati $z$ enostavno manipulacijo. Ukleščena kila je lahko še reponibilna, nereponibilna kila pa je lahko strangulirana ali ne. Po podatkih v literaturi je delež ukleščenih kil, ki so nereponibilne, 0,9-3 \%. Strangulacija ogroža prekrvitev vsebine ukleščene kile, ki jo povzroči napredujoče otekanje ukleščenih struktur zaradi venske in limfatične obstrukcije. Pri ukleščenju vsebin zaradi omenjenih patofizioloških fenomenov lahko pride do strangulacije že v 2 urah (3). Dolgotrajnejša motnja prekrvitve kilne vsebine lahko vodi do nekroze (odmrtja) ter s tem do predrtja in izlitja črevesne vsebine v kilno vrečo ali prosto $v$ trebušno votlino. Otrok s strangulirano vsebino ukleščene kilne vreče ima klinične znake peritonitisa ali sepse (4).

\section{Anatomija}

Dimeljski kanal poteka skozi trebušno steno. Vsebino kanala poleg žil predstavlja semensko povesmo pri dečkih in okrogli ligament (ligamentum rotundum) pri deklicah. Oblikuje ga aponevroza zunanje diagonalne trebušne mišice ( $m$. obliquuus externus abdominis) spredaj in prečna trebušna mišica in njena fascija ( $m$. transversus abdominis) zadaj. Zunanji dimeljski obroček oblikuje zunanja diagonalna trebušna mišica tik nad tuberklom sramnice in lateralno od njega. Notranji dimeljski obroček je $v$ transverzalni fasciji ter ga oblikujeta transverzalna mišica in notranja diagonalna trebušna mišica (m. obliquus internus abdominis). Pri otrocih je dimeljski kanal kratek in položen bolj pravokotno na trebušno steno, tako da je položaj zunanjega dimeljskega obročka nad notranjim dimeljskim obročkom $(1,5)$. Prav zaradi oblike kanala je tveganje razvoja dimeljske kile pri novorojenčkih večje, zlasti ob povišanem tlaku v trebušni votlini (mehansko predihavanje) (6).

\section{Embriologija}

Dimeljska kila nastane zaradi motnje v zapiranju podaljška potrebušnice (processus vaginalis). Podaljšek potrebušnice se oblikuje med drugim in tretjim mesecem nosečnosti iz potrebušnice, ki pokriva sprednjo trebušno steno in oblikuje nekakšen divertikel na ravni notranjega dimeljskega obročka. Med 7. in 9. mesecem nosečnosti se pri dečkih moda skozenj spustijo iz trebušne votline v mošnjo. Ko je proces zaključen, se podaljšek spontano zapre, običajno do drugega leta starosti (7). Pri deklicah se jajčniki spustijo podobno kot pri dečkih moda, le da trebušne votline ne zapustijo. Ekvivalent podaljška potrebušnice je pri deklicah Nuckov divertikel, peritonealni žepek, ki sega od maternice do velikih sramnih ustnic in se običajno spontano zapre do 7. meseca nosečnosti (8).

Glede na različno stopnjo zapiranja podaljška potrebušnice (PV) razlikujemo različne oblike herniacij. Če PV ostane široko odprt, kar omogoča, da se skozi notranji dimeljski obroček izboči črevo ali maščevje, gre za indirektno dimeljsko kilo. Če je PV skoraj zaprt, a omogoča pretakanje tekočine iz trebušne votline, nastane komunikantna hidrokela.

Kilna vreča običajno vsebuje tekočino, včasih črevo, pri deklicah tudi jajčnik, redkeje jajcevod ali celo del maternice. Indirektna dimeljska kila, ki je praviloma prisotna pri otrocih, gre skozi dimeljski kanal in se nahaja lateralno od globokih epigastričnih žil. Direktne kile, ki so pri otrocih redke in najpogosteje nastanejo kot zaplet po operativnem zdravljenju indirektne dimeljske kile (9), pa potekajo medialno od prej omenjenih žilnih struktur.

\section{Epidemiologija}

Pojavnost (incidenca) dimeljskih kil je večja pri dečkih, in sicer 3- do 4-krat. Pri obeh spolih je kila pogostejša na desni strani $(10,11)$. Pri dečkih je pojavnost največja $v$ prvem letu starosti $z$ vrhom v obdobju novorojenčka ( $v$ prvem mesecu starosti) $(1,11,12)$. Desnostranske dimeljske kile naj bi bile pogostejše zaradi kasnejšega spuščanja desnega moda in s tem kasnejšega zapiranja PV na desni strani. Obojestranske dimeljske kile se pojavljajo v približno $10 \%$ donošenih in pri skoraj $50 \%$ nedonošenih otrok $(13,14)$.

Ukleščena kila je prva manifestacija kile kar v $65 \%$ (15). Delež ukleščenih kil je večji desno kot levo (17 \% oz. $7 \%$ ) $(10,16)$. Zanimivo je, da so ukleščene kile pogostejše pri deklicah kot pri dečkih (17,2\% oz. $12 \%)$, pri deklicah pa je pogosteje kot črevo ukleščen jajčnik. Nekateri avtorji ugotavljajo, da je pogostost ukleščenja večja pri nedonošenčkih $(11,16)$, drugi menijo, da je situacija ravno obratna (6).

\section{Klinična slika}

Večina otrok z dimeljsko kilo ob pregledu nima jasne kile oziroma izbočenja v dimljah. Starši izbočenje opazijo ob napenjanju ali joku. Praviloma so ti otroci povsem brez težav in v ležečem položaju kile niti ne tipamo. Tudi manevri, s katerimi povečujemo tlak $v$ trebušni votlini (pihanje $v$ brizgo, napihovanje balona), so pogosto neučinkoviti. Včasih se starši k nam zatečejo zato, ker so $v$ dimljah otroka opazili izboklino, ki ne izgine. Kila je $v$ večini primerov mehka, reponibilna in neboleča na otip, kilni vrat je praviloma širok.

Otroci z ukleščeno kilo so razdražljivi in ob pregledu jokajo. Glede na trajanje ukleščenja se lahko razvijeta tudi 
napetost in povečan obseg trebuha. Otrok zavrača hrano in bruha. Klinični pregled otroka z ukleščeno kilo je v večini primerov diagnostičen. Zatipamo čvrsto izboklino, ki je občutljiva na palpacijo. Pri dečkih lahko sega v mošnjo, pri deklicah pa v velike sramne ustnice.

Dodatno slikovno diagnosticiranje v večini primerov ni potrebno, včasih pa nam morebitne nejasnosti v zvezi z izboklino v dimljah razjasni ultrazvočni pregled.

\section{Zdravljenje}

Zdravljenje dimeljske kile pri otroku je kirurško. Hitrost obravnave je odvisna od dejstva, ali je kila reponibilna ali ne. Vsako ukleščeno kilo moramo biti čim prej reponirati, s čimer preprečimo strangulacijo vsebine kilne vreče.

Tudi reponibilne dimeljske kile mora videti kirurg, ki ima izkušnje s tovrstno patologijo. Operativno zdravljenje naj bo hitro, da preprečimo zaplete, kot je ukleščenje. Do ukleščenja naj bi prišlo pri kar $13 \%$ otrok, ki že čakajo na operativni poseg, večinoma pri dojenčkih (do prvega leta starosti) (17-19), zato je zelo pomembno, da starše seznanimo z možnimi zapleti v smislu ukleščenja ter kliničnih znakih in simptomih.

Ukleščeno dimeljsko kilo moramo čim prej reponirati. Repozicija je lahko manualna ali kirurška. Za prvo se ne odločimo le, če je otrok vidno prizadet in ima znake peritonitisa, obstrukcije ali sepse ob gangreni črevesa (4). Manualna repozicija ali manipulacija kile je uspešna v 95-100 \% (21-23). Elektivno operacijo po uspešni repoziciji spremlja manjši delež zapletov kot nujna operativno repozicijo (10). Uspešnost manualne repozicije je premo sorazmerna s trajanjem ukleščenja in obratno sorazmerna z otrokovo starostjo (24). Priporočeno je, da poskrbimo za ustrezno analgezijo (opiatni analgetiki, npr. fentanil, ketamin, morfin), tudi sedacijo (midazolam) ob ustreznem spremljanju osnovnih življenjskih funkcij $(25,26)$. Če manu- alna repozicija ni uspešna, je potrebna operativna repozicija in $v$ večini nato hkrati tudi dokončna kirurška oskrba.

\section{Kirurška oskrba je raznovrstna.}

- Če je kila majhna, prazna in nedavno nastala, je najbolj običajen poseg visoka ligatura in ekscizija kilne vreče. Pri deklicah se moramo pred visoko ligaturo prepričati, da kila ne vsebuje jajčnika, jajcevoda ali dela maternice (27).

- Poleg visoke ligature in ekscizije lahko opravimo še plastiko notranjega dimeljskega obročka (vedno pri deklicah).

- Pri majhnih otrocih z dolgotrajnejšo in večjo kilo, zaradi katere je povsem raztegnjena tudi zadnja stena dimeljskega kanala, opravimo popolno rekonstrukcijo zadnje stene dimeljskega kanala (28).

- Laparoskopska hernioplastika, s katero se lahko izognemo disekciji edematoznih tkiv po ukleščenju, vidimo vsebino kilne vreče po repoziciji in lahko ocenimo vitalnost tkiv (npr. črevesa). Pregledamo tudi področje dimeljskega kanala na drugi strani glede morebitne prisotnosti kile (29-31).

- Pri dečkih, pri katerih najdemo v klili nespuščeno modo, hkrati napravimo še orhidopeksijo (1, 10, 20, 27).

- Pri ishemičnem črevesu se lahko odločimo za resekcijo in anastomozo, lahko tudi za odloženo, second-look operacijo. Praviloma je v takšnem primeru potrebna laparotomija.

Medtem ko so metode kirurške oskrbe precej standardne, je večji problem optimalna časovna umestitev operacije. S takojšnjo dokončno oskrbo kile po uspešni repoziciji sicer zmanjšamo tveganje ponovitve ukleščenja, a je lahko težavna tehnična izvedba. Zaradi otekline tkiv po ukleščenju se lahko poslabša anatomska preglednost in tako težje opredelimo morebitne hkrati prisotne direktne kile (32). Po drugi strani pa odlašanje $z$ dokončno oskrbo poveča tveganje ponovnega ukleščenja in potencialne potrebe po nujni operaciji. Tveganje ponovnega ukleščenja je v 0,5-120 dneh po prvem ukleščenju 16-35 \% (17, 33). Številni kirurgi zato otroka po uspešni repoziciji ukleščene kile navadno hospitalizirajo in ga nato po 24-48 urah operirajo. $\mathrm{V}$ izogib ponovnemu ukleščenju naj bi dokončno oskrbo izvedli v petih dneh ( $v$ dveh dneh pri nedonošenčkih) (33).

\section{Rezultati}

\section{Naše izkušnje}

V Univerzitetnem kliničnem centru Ljubljana smo na oddelku za otroško kirurgijo od leta 2015 do septembra 2019 elektivno operirali 897 dimeljskih kil. Otroci, starejši od 6 mesecev in brez pomembnih pridruženih bolezni, so bili obravnavani v okviru enodnevne bolnišnične oskrbe. $V$ tem obdobju smo obravnavali 32 ukleščenih kil (28 dečkov, 26 desno), v povprečju šest na leto. Predoperativna repozicija je bila uspešna pri 12 primerih, zato je bil dejanski delež ukleščenih kil v naši obravnavi 2,1 \%. Najmlajši bolnik je bil star 15 dni, najstarejši več kot 10 let, mediana starosti je bila 95,5 dneva. Med bolniki z ukleščeno kilo je bilo 5 nedonošenčkov. Pri 17 primerih od 20 je bilo ukleščeno črevo, pri treh četrtinah deklic pa jajčnik. V 19 primerih (od 32) smo napravili hernioplastiko, $v$ preostalih primerih zgolj herniektomijo. Resekcija ishemičnega črevesa je bila potrebna le pri enem bolniku, pri enem bolniku pa smo opravili laparoskopsko revizijo trebušne votline. V devetih primerih (28\%) se je kila prvič manifestirala z ukleščenjem.

Novorojenčki in dojenčki do 6. meseca starosti z dimeljsko kilo, zlasti ukleščeno, potrebujejo specializirano obravnavo. Glede specializirane kirurške obravnave se v zadnjih let trudimo, da bi v UKC Ljubljana zagotovili zadostno število za otroško kirurško patologijo ustrezno specializiranih kirurgov, ki bi delovali v timu s pediatri intenzivisti in 
anesteziologi, subspecialno usposobljenimi za delo z otroki.

Glede na najnovejše raziskave bi bilo smiselno, da pri otrocih z ukleščeno kilo, ki so mlajši od enega leta, napravimo repozicijo, po uspešni repoziciji pa jih premestimo v v specializirano enoto otroške kirurgije za dokončno kirurško oskrbo. Če repozicija ni bila uspešna, bolnika ustrezno pripravimo in stabiliziramo ter opravimo njuni transport.

\section{Zaključek}

Po navedbah v literaturi ukleščene kile predstavljajo 0,9-3 \% vseh dimeljskih kil (1). Tudi pri nas je delež dimeljskih kil v opisanem razponu, medtem ko so ostale značilnosti primerljive z rezultati, opisanimi v literaturi.

Smiselno je, da z ustrezno usposobljenim osebjem, ki optimalno poskrbi za otrokovo oskrbo pred operacijo ter za medoperativno in pooperativno podporo, ukleščene kile oskrbimo v naši ustanovi. Zgodnja obravnava novorojenčka, ki ima kilo, zmanjša tveganje ukleščenja. Če do ukleščenja vendarle pride, ga moramo čim prej prepoznati in kilo reponirati.

\section{Literatura}

1. Kapur P, Caty MG, Glick PL. Pediatric hernias and hydroceles. Pediatr Clin North Am 1998; 45: 773-89.

2. Grosfeld JL. Current concepts in inguinal hernia in infants and children. World J Surg 1989; 13: 506-15

3. Houben $\mathrm{CH}$, Chan KWE, Mou JWC, Tam YH, Lee $\mathrm{KH}$. Irreducible inguinal hernia in children: how serious is it? Journal of Ped Surg 2015; 50 : 1174-6

4. Abdulhai SA, Glenn IC, Ponsky TA. Incarcerated Pediatric Hernias. Surg Clin N Am 2017; 97 129-45.

5. Iason A. Hernia in infancy and childhood. Am J Surg 1945; 68: 287-96.

6. Misra D, Hewitt G, Potts SR, Brown S, Boston VE. Inguinal herniotomy in young infants, with emphasis on premature neonates. J Pediatr Surg 1994; 29: 1496-8.

7. Rowe MI, Copelson LW, Clatworthy HW. The patent processus vaginalis and the inguinal hernia. J Pediatr Surg 1969; 4: 102-7.

8. Aiken JJ. Inguinal hernias. In: Nelson Textbook of Pediatrics, 17th, Behman RE, Kliegman RM, Jenson HB. (Eds), Saunders, Philadelphia; 2004.

9. Bronsther B, Abrams MW, Elboim C. Inguinal hernias in children-a study of 1,000 cases and a review of the literature. J Am Med Womens Assoc 1972; 27: 522-5.

10. Skoog SJ, Conlin MJ. Pediatric hernias and hydroceles. The urologist's perspective. Urol Clin North Am 1995; 22: 119-30.

11. Pan ML, Chang WP, Lee $\mathrm{HC}$, Tsai $\mathrm{HL}$, Liu CS, Liou DM et al. A longitudinal cohort study of incidence rates of inguinal hernia repair in 0to 6-year-old children. J Pediatr Surg 2013; 48: 2327-31.

12. Aboagye J, Goldstein SD, Salazar JH, Papandria D, Okoye MT, Al-Omar K et al. Age at presentation of common pediatric surgical conditions: Reexamining dogma. J Pediatr Surg 2014; 49: 995-9.

13. Rescorla FJ, Grosfeld JL. Inguinal hernia repair in the perinatal period and early infancy: clinical considerations. J Pediatr Surg 1984; 19: 832-7.

14. Rowe MI, Clatworthy HW Jr. The other side of the pediatric inguinal hernia. Surg Clin North Am 1971; 51: 1371-6.

15. Stylianos S, Jacir NN, Harris BH. Incarceration of inguinal hernia in infants prior to elective repair. J Pediatr Surg 1993; 28:5 82-3.

16. Rowe MI, Clatworthy HW. Incarcerated and strangulated hernias in children. A statistical study of high-risk factors. Arch Surg 1970; 101 : 136-9.

17. Clatworthy WH Jr, Thompson AG. Incarcerated and strangulated inguinal hernia in infants: a preventable risk. J Am Med Assoc 1954; 154 123-6.

18. Stephens BJ, Rice WT, Koucky CJ, Gruenberg JC. Optimal timing of elective indirect inguinal hernia repair in healthy children: clinical considerations for improved outcome. World J Surg 1992; 16: 952-7.

19. Zamakhshary M, To T, Guan J, Langer JC. Risk of incarceration of inguinal hernia among infants and young children awaiting elective surgery. Can Med Assoc J 2008; 179:1001-5.

20. Puri P, Guiney EJ, O’Donnell B. Inguinal hernia in infants: the fate of the testis following incarceration. J Pediatr Surg 1984; 19: 44-6.

21. Stringer MD, Higgins M, Capps SN, Holmes SJ. Irreducible inguinal hernia. Br J Surg 1991; 78 : 504-5

22. Gahukamble DB, Khamage AS. Early versus delayed repair of reduced incarcerated inguinal hernias in the pediatric population. J Pediatr Surg 1996; 31: 1218-20.

23. Moss RL, Hatch El Jr. Inguinal hernia repair in early infancy. Am J Surg 1991; 161: 596-9.

24. Davies N, Najmaldin A, Burge DM. Irreducible inguinal hernia in children below two years of age. Br J Surg 1990; 77: 1291-2.

25. Goldman RD, Balasubramanian S, Wales P, Mace SE. Pediatric surgeons and pediatric emergency physicians' attitudes towards analgesia and sedation for incarcerated inguinal hernia reduction. J Pain 2005; 6: 650-5.
26. Al-Ansari K, Sulowski C, Ratnapalan S. Analgesia and sedation practices for incarcerated inguinal hernias in children. Clin Pediatr (Phila) 2008; 47: 766-9.

27. Paidas C, Kayton ML. Inguinal hernia. In: Oski's Pediatrics: Principles and Practice, 4th, McMillan JA, DeAngelis CD, Feigin RD et al., eds. Lippincott Williams \& Wilkins, Philadelphia; 2006 28. Othersen HB Jr. The pediatric inguinal hernia. Surg Clin North Am 1993; 73:853-9.

29. Koivusalo A, Pakarinen MP, Rintala RJ. Laparoscopic herniorraphy after manual reduction of incarcerated inguinal hernia. Surg Endosc 2007; 21: 2147-9.

30. Chan KWE, Lee KH, Tam YH, Sihoe JD, Cheung ST, Mou JW. Laparoscopic inguinal hernia repair by the hook method in emergency setting in children presenting with incarcerated inguinal hernia. J Pediatr Surg 2011; 46: 1970-3.

31. Esposito C, Turial S, Alicchio F, Laffolie JD, Castagnetti M, Krause K et al. Laparoscopic repair of incarcerated inguinal hernia. A safe and effective procedure to adopt in children. Hernia 2013; 17: 235-9

32. Steinau G, Treutner KH, Feeken G, Schumpelick $V$. Recurrent inguinal hernias in infants and children. World J Surg 1995; 19: 303-6.

33. Gahukamble DB, Khamage AS. Early versus delayed repair of reduced incarcerated inguinal hernias in the pediatric population. J Pediatr Surg 1996; 31: 1218-20.

asist. Polona Studen Pauletič, dr. med. kontaktna oseba / contact person

Oddelek otroške kirurgije

Univerzitetni klinični center Ljubljana Bohoričeva 20, 1525 Ljubljana, Slovenija e-naslov: polona.studen.pauletic@kclj.si

prispelo / received: 13. 1. 2020 sprejeto / accepted: 2. 3. 2020

Studen Pauletič P. Ukleščene dimeljske kile pri otrocih. Slov Pediatr 2020; 27(2): 77-80. https:// doi.org/10.38031/ slovpediatr-2020-2-05 